\title{
Erratum zu: Handbuch der Baugeologie und Geotechnik
}

Wolfgang Dachroth 
Folgende Änderungen wurden ausgeführt:

Seite XXI: Der Hauptautor Prof. Dr. Wolfgang R. Dachroth wurde im Autorenverzeichnis nicht erwähnt.

\section{Prof. Dr. Wolfgang R. Dachroth}

Geologisch-Paläontologisches Institut

Ruprecht-Karls-Universität Heidelberg

(im Ruhestand seit 2003)

Kapitel 2, Seite 172, rechte Spalte: Der Verweis auf Abschnitt 2.6.8 war falsch und wurde zu Abschnitt 2.6.12 korrigiert. 